\title{
PSICOLOGIA
}

\section{PRIMEIRO EMPREGO: O PERFIL DO ADOLESCENTE E O PAPEL DO PSICÓLOGO FRENTE A ESTA NOVA ETAPA}

\author{
DOI: http://dx.doi.org/10.31072/rcf.v8i2.546 \\ FIRST JOB: THE PROFILE OF THE TEENAGER AND THE ROLE OF THE \\ PSYCHOLOGIST IN FRONT OF THIS NEW STAGE
}

Hellen Cristina Pereira Moraes ${ }^{1}$; Victor Hugo Coelho Rocha²; Gésica Borges Bergamini3; Evelin Samuelsson ${ }^{4}$; Cristielli Joner ${ }^{5}$; Luiz Fernando Schneider ${ }^{6}$; Pérsia Regina Menz ${ }^{7}$.

\begin{abstract}
RESUMO: A inserção do jovem no mercado de trabalho é um dos complexos processos que compõem a chamada transição para a vida adulta e é justamente nessa fase que circula todos os medos a respeito da primeira colocação no mercado de trabalho. O presente artigo discute os impasses da inserção profissional e o perfil do adolescente de 14 a 17 anos que estão em busca de seu primeiro emprego e o papel do psicólogo diante desta etapa vivenciada por este sujeito. Objetivos: Analisar os impasses da inserção profissional e o perfil dos adolescentes que estão em busca de seu primeiro emprego e o papel do psicólogo diante desta etapa vivenciada por este indivíduo, além do mais, identificar qual o perfil de liderança predominante no grupo que buscam tal vaga, quais os principais sentimentos dos pesquisados frente à busca e enfatizar a importância do psicólogo no âmbito organizacional. Métodos: Foi aplicado questionários que se referem ao IAT - Inventário de Atitudes no Trabalho o qual pretende colher dados sobre as atitudes do sujeito em relação a cinco tópicos básicos do trabalho e a Escala de Bem-Estar Subjetivo (EBES) que busca compreender a avaliação que as pessoas fazem de suas vidas. Resultados e Discussão: Os dados obtidos revelam que as crenças e sentimentos pertencentes a tais sujeitos frente à busca dessa colocação no mercado de trabalho são positivas, além do mais, apresentam um perfil de liderança maduro o que permite observar a eficácia no preparo de tais jovens para 0 mercado de trabalho.
\end{abstract}

Palavras-chave: Primeiro emprego. Avaliação psicológica. Adolescência. Psicologia.

\footnotetext{
1 Acadêmica de Psicologia da Faculdade de Educação e Meio Ambiente - FAEMA. Autora principal desta pesquisa. Email: studiovictorocha@gmail.com. ORCID: https://orcid.org/0000-0002-3507-5067;

2 Acadêmico de Psicologia da Faculdade de Educação e Meio Ambiente - FAEMA. Autor principal desta pesquisa. Email: studiovictorocha@gmail.com. ORCID: https://orcid.org/0000-0002-4783-8359;

${ }_{3}$ Mestra, Psicóloga e Orientadora desta pesquisa. Professora da Faculdade de Educação e Meio Ambiente FAEMA. E-mail: gpensemagro@hotmail.com. ORCID: https://orcid.org/0000-0003-0598-5366;

4 Mestra, Bióloga e Colaboradora desta pesquisa. Professora da Faculdade de Educação e Meio Ambiente FAEMA. E-mail: evelin.samuelsson@faema.edu.br. ORCID: https://orcid.org/0000-0002-0508-2709;

5 Especialista, Fisioterapeuta e Colaboradora desta pesquisa. Professora da Faculdade de Educação e Meio Ambiente - FAEMA. E-mail: cristielle.joner@faema.edu.br. ORCID: https://orcid.org/0000-0002-7476-667X;

6 Especialista, Fisioterapeuta e Colaborador desta pesquisa. Professor da Faculdade de Educação e Meio Ambiente - FAEMA. E-mail: luiz.schneider@faema.edu.br. ORCID: https://orcid.org/0000-0002-7945-2581;

7 Mestra, Fisioterapeuta e Colaboradora desta pesquisa. Professora da Faculdade de Educação e Meio Ambiente - FAEMA. E-mail: persia.menz@faema.edu.br. ORCID: https://orcid.org/0000-0002-1052-6650.
} 
ABSTRACT: The insertion of young people in the labor market and one of the complex processes that make up a transition call for an adult life and it is precisely at this stage that all fears circulate about the first place in the labor market. The present article discusses the impasses of the professional insertion and the profile of the adolescence of 14 to 17 years who are in search of their period of employment and role of the psychologist before this stage experienced by this subject. Objectives: To analyze the impasses of the professional insertion and the profile of the adolescents who are in search of their first job and role of the psychologist before this stage experienced by this individual, besides, to identify which predominant profile of leadership in the group that seeks such a wave, What are the main feelings of the researched in the search and emphasize the importance of the psychologist in the organizational field. Methods: We applied questionnaires that refer to the IAT - Attitudes Inventory at Work, which aims to collect data on the subjects' attitudes to five basic topics of work and the Subjective Well-Being Scale (EBES), which seeks an evaluation that how people make their lives. Results and Discussion: The data obtained reveal that as beliefs and feelings belonging to so many subjects facing the search for job placement are positive, in addition, a mature leadership profile what you expect to observe the effectiveness in preparing such young people for the labor market.

Keywords: First job. Psychological assessment. Adolescence. Psychology.

\section{INTRODUÇÃO}

No Brasil, o mercado de trabalho juvenil indica que os jovens entre 15 e 29 têm elevada participação na População Economicamente Ativa, entre os quais se destacam as coortes etárias de 15 a 17 anos e 18 e 24 anos, idades nas quais os jovens ainda precisam aumentar sua formação escolar. O desemprego dos jovens tem impactos de curto e de longo prazo, podendo aumentar o risco de pobreza, menor qualificação e exclusão social, assim como causar perda de motivação e problemas de saúde físicos e mentais, além do mais, o longo período de busca de emprego pode levar a períodos maiores de desemprego ao longo do ciclo de trabalho, perda de qualificação e de produtividade e perda de renda futura que repercutirão em âmbito macro com perda de crescimento e produtividade (1).

A proposta deste artigo, intitulado como "Primeiro Emprego: O perfil do adolescente e o papel do psicólogo frente a esta nova etapa" é apresentar os dados da pesquisa desenvolvida no Grupo de Voluntários - Programa Jovem Aprendiz no município de Ariquemes/RO, no período de agosto a setembro de 2017.

Este trabalho discute e visa analisar os impasses da inserção profissional e o perfil do adolescente de 14 a 17 anos que estão em busca de seu primeiro emprego e o papel do psicólogo diante desta etapa vivenciada por este indivíduo, além do mais, investigar e identificar qual o perfil de liderança predominante no grupo que buscam a primeira vaga de emprego, 
quais os principais sentimentos dos pesquisados frente à busca do primeiro emprego e enfatizar a importância do psicólogo no âmbito organizacional.

Sua relevância centra-se no entendimento de que, apesar do aumento dos níveis de desemprego no nosso país, os jovens continuam a serem preparados para se tornarem trabalhadores assalariados, e o questionamento girou-se em torno sobre qual é o perfil desses adolescentes que se preparam para alcançar sua primeira vaga no mercado de trabalho e quais as crenças e sentimentos que giram em torno desses sujeitos nesse processo que faz parte da constituição desse grupo para a vida adulta?

Foi realizado aplicações de inventários psicológicos, sendo estes, o I.A.T - Inventário de Atitudes no Trabalho e a EBES -Escala do Bem Estar Subjetivo, que revelaram que as crenças pertencentes a tais sujeitos frente à busca dessa colocação no mercado de trabalho são positivas, além do mais, apresentam um perfil de liderança maduro o que permite observar a eficácia no preparo de tais jovens para o mercado de trabalho.

\section{FUNDAMENTAÇÃO TEÓRICA}

\subsection{Adolescência}

A Adolescência é o período de transição entre a infância e a vida adulta, caracterizado pelas mudanças do desenvolvimento físico, mental, emocional, sexual e social e pelos empenhos do indivíduo em alcançar os objetivos relacionados às expectativas culturais da sociedade em que vive. Tal período iniciase com as mudanças corporais da puberdade e finaliza quando o indivíduo estabiliza seu crescimento e sua personalidade, obtendo progressivamente sua independência econômica, além da integração em seu grupo social (2).

A inserção na vida profissional é um dos processos que marcam a transição para a vida adulta e o enfrentamento das responsabilidades adultas, sendo elas: a autorregulação, organização pessoal e financeira, lidar com cobranças e riscos, etc. Essa fase de transição, de mudanças, de adaptação e de ajustamento é um momento de confrontação entre o fim da infância e as reais responsabilidades adultas, seja de uma profissão ou tarefa específica, ou do mundo adulto como um todo (3).

\subsection{Características dos adolescentes} frente à busca ao primeiro emprego

À medida que lida com seus conflitos interiores e mudanças fisiológicas, o adolescente se depara em uma sociedade contraditória e cuja complexidade gera muita desordem na sua cabeça, defrontando-se atualmente com uma cultura em intensa transformação, valores 
velhos e decadentes se contrapondo a novas ideias e conceitos, sem que exista um tempo necessário para sua assimilação (4).

Segundo Bravo(5) a adolescência além de ser uma sofrida privação de reconhecimento e independência, é também uma fase de transição. É essencial que haja um olhar da sociedade amplo, para contribuir de maneira que esta passagem da infância para a vida adulta aconteça de forma saudável.

A adolescência é caracterizada por um momento de dificuldades, conflitos e alterações de humor, também é um momento de intensa exploração e descoberta de diversas oportunidades e novas responsabilidades ${ }^{(6)}$.

\subsection{Instrumentos psicológicos} utilizados para identificação do perfil estudado

A avaliação psicológica caracterizase por um processo de coleta de dados, cujo procedimento inclui métodos $\mathrm{e}$ técnicas de investigação, entre eles os testes psicológicos, este que são instrumentos específicos do psicólogo. Esses instrumentos são extremamente uteis pois, podem oferecer informações importantes sobre os indivíduos que estão sendo avaliados $(7)$.

De acordo com Baumgartl, Pagano e Lacerda(8) $^{(8)}$ no processo de seleção, o teste psicológico é utilizado com o propósito de avaliar conhecimentos e aptidões do candidato no momento em que ele compete a uma vaga, e a partir daí tentar predizer a sua performance associado ao trabalho almejado.

Vale salientar que a aplicação de testes psicológicos é um dos instrumentos mais importantes e imprescindíveis num processo de seleção, pois auxiliam o selecionador a traçar um perfil mais preciso do candidato. Há evidências de que os selecionadores estão interessados em contratar um profissional que atenda ao perfil da vaga e que se desenvolva de acordo com a cultura da empresa, adaptando-se aos requisitos da organização. O conjunto de informações colhidas evidencia se 0 profissional abrange o perfil necessário à empresa, e se possui potencial ou não para desempenhar as atividades propostas ${ }^{(7)}$.

Os instrumentos utilizados para coleta de dados do presente estudos foram: Inventário de Atitudes no Trabalho (IAT) e a Escala de Bem-Estar Subjetivo.

A Escala de Bem-estar Subjetivo EBES, é composta por três fatores: afeto positivo (21 itens), afeto negativo (26 itens) e satisfação com a vida (13 itens). O instrumento é composto por duas subescalas de resposta tipo Likert de cinco pontos. Na primeira parte da escala, os 
itens vão do número 1 ao 47 e descrevem afetos positivos e negativos, devendo 0 sujeito responder como tem se sentido ultimamente, em uma escala na qual um significa nem um pouco e cinco significa extremamente. $\mathrm{Na}$ segunda parte da escala, os itens variam do número 48 ao 60 e descrevem julgamentos relativos à avaliação de satisfação ou insatisfação com a vida, devendo ser respondidos em uma escala na qual um significa discordo plenamente e cinco significa concordo plenamente ${ }^{(9)}$.

O Inventário de Atitudes no Trabalho - IAT é um questionário composto por 60 itens, no qual pretende colher alguns dados sobre suas atitudes em relação a cinco tópicos básicos do trabalho, sendo divididos nas seguintes formas: com relação à tomada de decisão (12 itens), com relação à programação das atividades (12 itens), com relação à execução das atividades (12 itens), com relação ao controle das atividades (12 itens), e por fim, com relação às mudanças na organização (12 itens). Em cada item o indivíduo em que está sendo submetido ao inventário possui 04 alternativas sendo:

0 - Nunca sou desse modo;

1 - Às vezes, sou desse modo;

2 - Na maioria das vezes, sou desse modo;
O mesmo deve assinalar um " $X$ " de acordo com o grau de correspondência ao seu modo de ser (10).

É importante ressaltar que os instrumentos utilizados houveram a aceitação e concordância com a participação e objetivos do estudo por parte das pessoas submetidas a eles através do Termo de Consentimento Livre e Esclarecido.

\subsection{Papel do psicólogo frente à} identificação e suporte ao indivíduo que busca o primeiro emprego

Ao longo da história, a Psicologia ingressou nas empresas através da seleção e avaliação de pessoas. $O$ desenvolvimento de quaisquer atividades dentro ou fora das organizações depende significativamente das condições das empresas, e, especialmente, do profissional que as realiza. Visto que 0 mercado atual é extremamente competitivo, e exige cada vez mais competência técnica e interpessoal, de tal modo que tanto as condições pessoais (crenças, valores, postura, capacidade para colocar ideias) quanto às técnicas (formação acadêmica, cursos de especialização, domínio de tecnologias) auxiliarão a determinar o espaço de trabalho do profissional e a credibilidade de suas propostas ${ }^{(7)}$.

3 - Sempre sou desse modo. 
Becker(4) postula que a sociedade ocidental não contribui em nada para facilitar 0 conflito que 0 adolescente vivencia, enquanto, de outro modo, tenta diminui-lo ou abafá-lo. E é preciso lembrar também que, mesmo dentro dessa sociedade, a adolescência pode assumir formas muito diversas.

A área da Psicologia que passou por modificações tão profundas durante 0 último século foi a que atua no setor de recursos humanos. Tais modificações se deram pela automação e pela crise econômica que mudaram o perfil do emprego e, pelos novos métodos administrativos, por exemplo: a terceirização, demonstrando uma modificação acelerada (7).

Segundo Godoy e Noronha ${ }^{(7)}$ das atribuições do psicólogo, é preparar-se para refletir a respeito das profundas mudanças que estão ocorrendo na sociedade, atentando-se para as novas demandas que surgem, de modo a desempenhar sua profissão de forma exitosa, prestando um bom serviço.

Independentemente da ferramenta que se utilize na seleção profissional cabe ao psicólogo manter o ciclo de satisfação de ambas as partes - empregador e colaborador, procurando incluir um profissional qualificado de acordo com as competências deste e assimilando com as necessidades da empresa. O colaborador satisfeito com a sua ocupação apresenta uma disposição maior para atuar com assertividade e eficácia, e, consequentemente, agregará mais valor para a empresa, satisfazendo ambos os lados e realizando um bom trabalho ${ }^{(7)}$.

\section{MÉTODOS}

A aplicação dos questionários foi realizada no Grupo de Voluntários Menor Aprendiz no município de Ariquemes Rondônia e atingiu adolescentes de quatorze a dezessete anos que visam alcançar a primeira vaga de emprego. As atividades aqui descritas referem-se àquelas desenvolvidas no período de agosto a setembro de 2017. Identificou-se que o perfil que se dispôs participar da aplicação dos questionários é de pessoas provenientes de famílias de baixa renda.

Os questionários aplicados referemse ao IAT- Inventário de Atitudes no Trabalho o qual pretende colher dados sobre as atitudes do sujeito em relação a cinco tópicos básicos do trabalho e a Escala de Bem-Estar Subjetivo (EBES) que busca compreender a avaliação que as pessoas fazem de suas vidas.

\section{RESULTADOS E DISCUSSÕES}

A aplicação se realizou a partir de dois encontros que teve duas horas e meia de duração cada encontro, a aplicação foi desenvolvida por alunos de graduação do 
curso de psicologia e ocorreu somente após a autorização da instituição e dos participantes por meio da assinatura do termo de consentimento afim de respaldar os fins éticos da pesquisa.

Quanto aos participantes houve o envolvimento de 30 adolescentes com atenção continuada durante a aplicação do inventário e da escala.

O projeto desenvolveu-se em duas fases, no primeiro momento foi de familiarização dos acadêmicos com a organização, foram realizadas observações da organização e da turma de participantes do projeto Menor Aprendiz, e posteriormente a aplicação do Inventário de Atitudes no Trabalho, neste inventario não há respostas certa ou errada, a melhor resposta será a que representar com maior sinceridade a maneira de ser do sujeito e seu estilo de liderança. As diferentes características nele descritas, definem o modo do sujeito de liderar e não a sua habilidade, para cada questão existem quatro maneiras de lidar com a situação citada sendo "Nunca sou desse modo; Ás vezes sou desse modo; Na maioria das vezes sou desse modo; Sempre sou desse modo" e os perfis de liderança são: PC - Pai Crítico; PN - Pai Nutritivo; A - Adulto; CR Criança Rebelde; CS - Criança Submissa; CL - Criança Livre.
De acordo com Matos(10), o perfil PCPai Crítico é responsável pelas atitudes e comportamentos de crítica, de punição repreensão. Pode apresentar-se positiva ou negativamente, conforme as repercussões de seu comportamento sobre a outra pessoa. O PN- Pai Nutritivo é a parte que apoia, aprova, compreende os erros de outra pessoa, protege e perdoa. O altruísmo é a expressão típica desse subestado do ego. Entretanto, pode se apresentar negativo, quando exagera a proteção, tolhendo a atitude do outro, quando perdoa demais, enfim quando dá em excesso.

O perfil A - Adulto é a parte da personalidade responsável pela coleta, análise dos dados e tomada de decisão. Obtém suas informações de três fontes: o ambiente, as gravações, Pai e as gravações criança. Também pode ser negativo socialmente, um ladrão ou um assassino profissional são exemplos eloquentes de pessoas com adultos bem desenvolvidos. A CR- Criança Rebelde é a parte da criança adaptada cuja característica principal é ser do contra, está constantemente pronta para dizer um não, mesmo quando não tem razão. A CS - Criança Submissa é a parte da criança adaptada que recebe os castigos e críticas do pai crítico, responsável pelas atitudes de submissão, covardia e medo 
exagerado. Quando é positiva, sua atitudes e comportamentos são de conformidade com as normas e princípios do ambiente em que se encontra, demonstrando aceitação e cumprimento dos mesmos. Por fim, o perfil CL - Criança Livre representa o nosso depósito de emoções adequadas, de criatividade, de espontaneidade, da intuição. No segundo encontro foi realizado a aplicação da Escala de Bem-Estar Subjetivo (EBES), este questionário é dividido em duas subescalas, a primeira consiste de algumas palavras que descrevem diferentes sentimentos e emoções as quais os participantes possivelmente tem sentido recentemente, tais como aflição, angustia, alegria, apreensão, preocupação, disposição, irritabilidade, interesse, tédio, atenção, transtorno, ânimo, determinação, chateação, entre outros. A segunda subescala consiste em algumas frases que pode indicar opiniões que o sujeito tem sobre a sua própria vida no momento atual.

No momento de propor a aplicação dos questionários para os adolescentes, buscou-se facilitar a compreensão dos mesmos quanto aos questionários $e$ objetivos deste. Procurou-se também, incentivar as interações entre os adolescentes desmitificando a posição de analisados diante dos estagiários de psicologia, para auxiliar a compreensão dos participantes em relação aos questionários e para o desenvolvimento do presente trabalho foi realizado levantamento bibliográfico e leituras pertinentes ao tema de trabalho, planejamento das atividades a serem desenvolvidas e apresentação do projeto para a turma de menores aprendizes da organização escolhida.

De acordo com o primeiro objetivo do trabalho, procurou-se investigar $\mathrm{e}$ identificar qual o perfil de liderança predominante no grupo de participantes de 14 a 17 anos que buscam a primeira vaga de emprego. As respostas obtidas foram agrupadas em duas tabelas, a primeira destacado os tipos de perfis de liderança e os respectivos resultados obtidos de cada participante e a segunda tabela destacando o resultado geral, destacando os dois perfis predominante.

$\mathrm{Na}$ Tabela 1 foram enumerados 06 grupos de perfil de liderança proposto pelo inventário. Foram organizados em ordem crescente de acordo com a somatória da pontuação obtida dos participantes. Dos 06 instrumentos apresentados, 02 foram destacados como os principais perfis de liderança sendo estes: Adulto (A) e Pai Nutritivo (PN). 
Tabela 1 - Grupos de perfil de Liderança.

\begin{tabular}{lccc}
\hline \multicolumn{4}{c}{ INVENTÁRIO DE ATITUDES NO TRABALHO - IAT } \\
\hline \multicolumn{1}{c}{ GRUPOS } & TOTAL & MÉDIA & DESVIO PADRÃO \\
\hline Adulto (A) & 625 & 20,83 & 4,14 \\
Pai Nutritivo (PN) & 609 & 20,30 & 4,14 \\
Criança Submissa (CS) & 477 & 15,90 & 4,23 \\
Pai Crítico (PC) & 434 & 14,46 & 4,23 \\
Criança Livre (CL) & 295 & 9,83 & 4,33 \\
Criança Rebelde (CR) & 243 & 8,10 & 5,28 \\
\hline
\end{tabular}

Gráfico 1 - Média dos grupos e perfis de liderança.

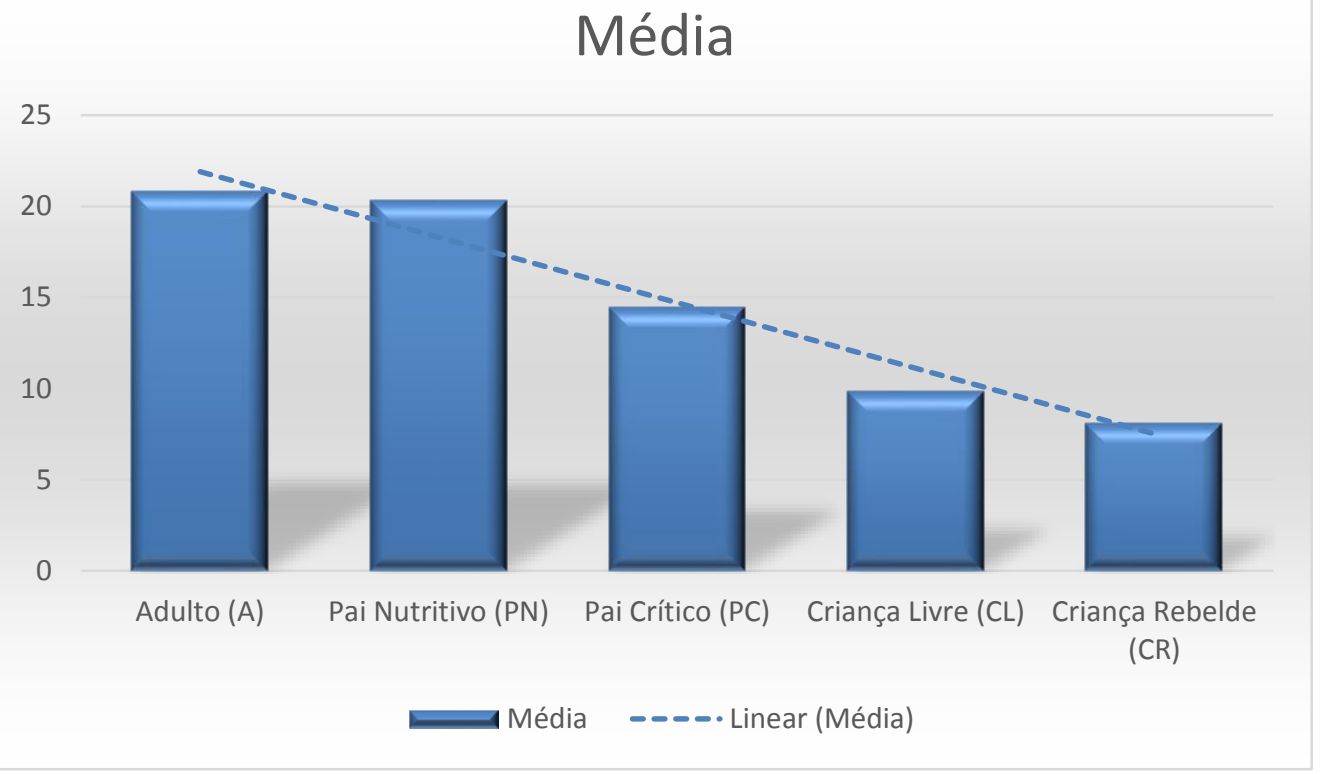

Os resultados desta pesquisa embora não devam ser generalizados, permitem uma reflexão a respeito do perfil predominante de liderança que os participantes da pesquisa apresentam. Bunchaft \& Vasconcellos ${ }^{(12)}$ consideram oportuno a utilização da Análise Transacional como substrato teórico para a interpretação dos testes projetivos, a análise estrutural em Análise Transacional aborda a personalidade como sendo constituída por três Estados do Eu, que se expressam por comportamentos visíveis.
Estado do Eu Adulto, perfil predominante na pesquisa, é o "computador" da personalidade, corresponde àquilo que é pensado. Um colaborador que apresente um perfil de liderança "Adulto" dentro de uma organização será um sujeito responsável, informado, ético e focado nas metas da organização e nos objetivos que este propuser. Pode apresentar algumas dificuldades quanto a sociabilidade nesse ambiente de trabalho podendo ser 
considerado um pouco egoísta e ambicioso.

O perfil de liderança "Pai Nutritivo" se destaca por apresentar condutas afetivas e protetoras dentro da organização, o pai nutritivo é a parte que apoia, aprova, compreende os erros de outra pessoa, protege e perdoa, este sujeito pode ser prejudicado quando exagera na proteção podendo

prejudicar.

\begin{tabular}{|c|c|c|c|}
\hline \multicolumn{4}{|c|}{ Escala de Bem Estar Subjetivo } \\
\hline \multicolumn{4}{|c|}{ Subescala 1} \\
\hline & Total & Média & Desvio Padrão \\
\hline Bem & 121 & 4,03 & 0,85 \\
\hline Empolgado & 118 & 3,93 & 0,94 \\
\hline Determinado & 117 & 3,90 & 0,92 \\
\hline Decidido & 115 & 3,83 & 1,05 \\
\hline Interessado & 114 & 3,80 & 1,18 \\
\hline Ansioso & 113 & 3,76 & 1,16 \\
\hline Animado & 113 & 3,76 & 0,97 \\
\hline Disposto & 93 & 3,10 & 1,18 \\
\hline Contente & 92 & 3,06 & 1,12 \\
\hline Dinâmico & 92 & 3,06 & 0,90 \\
\hline Inspirado & 90 & 3,00 & 1,25 \\
\hline Engajado & 90 & 3,00 & 1,25 \\
\hline Produtivo & 89 & 2,96 & 1,12 \\
\hline Apreensivo & 89 & 2,30 & 0,98 \\
\hline Amável & 85 & 2,83 & 1,17 \\
\hline Alegre & 85 & 2,83 & 1,05 \\
\hline Agradável & 84,8 & 2,93 & 1,12 \\
\hline Indeciso & 84 & 2,80 & 1,09 \\
\hline Preocupado & 83 & 2,83 & 1,41 \\
\hline Receoso & 83 & 2,76 & 1,19 \\
\hline Envergonhado & 83 & 2,76 & 1,25 \\
\hline Irritado & 82 & 2,73 & 1,25 \\
\hline Atento & 82 & 2,73 & 1,25 \\
\hline Entusiasmado & 82 & 2,73 & 1,20 \\
\hline Ativo & 82 & 2,73 & 0,98 \\
\hline Impaciente & 77 & 2,56 & 1,30 \\
\hline Estimulado & 77 & 2,56 & 0,93 \\
\hline Seguro & 76 & 2,53 & 1,16 \\
\hline Agitado & 72 & 2,40 & 0,93 \\
\hline Aborrecido & 68 & 2,26 & 1,14 \\
\hline Deprimido & 68 & 2,26 & 1,04 \\
\hline Entediado & 68 & 2,26 & 0,78 \\
\hline
\end{tabular}




\begin{tabular}{llll}
\hline & & & Continuação \\
\hline Alarmado & 67 & 2,23 & 1,04 \\
\hline Vigoroso & 66 & 2,20 & 1,12 \\
\hline Aflito & 66 & 2,02 & 0,99 \\
\hline Angustiado & 65 & 2,16 & 1,01 \\
\hline Desanimado & 65 & 2,16 & 0,98 \\
\hline Tenso & 63 & 2,10 & 0,99 \\
\hline Assustado & 62 & 2,06 & 1,22 \\
\hline Nervoso & 61 & 2,03 & 1,21 \\
\hline Amedrontado & 61 & 2,03 & 0,96 \\
Chateado & 60 & 2,00 & 1,20 \\
\hline Triste & 60 & 2,00 & 1,08 \\
Agressivo & 58 & 1,93 & 0,94 \\
\hline Incomodado & 55 & 1,83 & 0,83 \\
Abatido & 55 & 1,83 & 0,79 \\
Transtornado & 44 & 1,46 & 0,77 \\
\hline
\end{tabular}

Os resultados desta pesquisa permitem identificar que os principais sentimentos encontrados em tais sujeitos frente ao primeiro emprego.

A aplicação da Escala de Bem-Estar Subjetivo (EBES) teve como objetivo nesta pesquisa identificar quais os principais sentimentos dos pesquisados frente a

Gráfico 2 - Resultado Subescala 01. busca do primeiro emprego. No Gráfico 02 foram destacados os 06 principais sentimentos apresentados pelos participantes da pesquisa que se encontram nesse momento de busca da primeira vaga de emprego.

\section{ESCALA DE BEM-ESTAR SUBJETIVO}
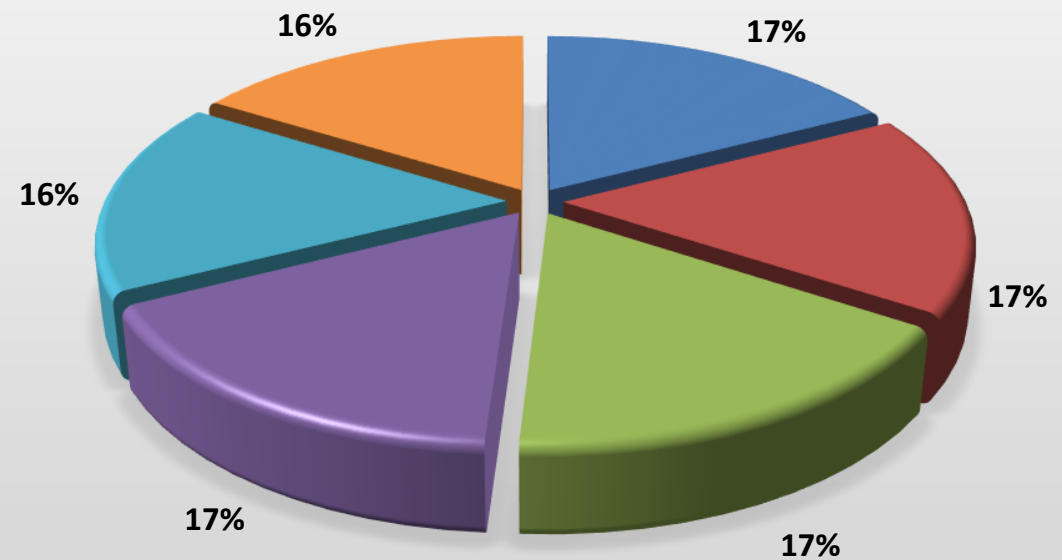

\Bem $\square$ Empolgado $\square$ Determinado $\square$ Decidido $\mathbf{\Delta}$ Interessado $\square$ Ansioso 
Albuquerque \& Tróccoli(13) postula que o bem estar subjetivo sofre influência cultural, o sentido das experiências dos indivíduos é construído socialmente através de crenças, pressuposições e expectativas sobre 0 mundo. Dentre 0 vasto campo que tal escala consegue analisar encontra-se 0 de qualidade de vida, termo o qual pode relacionar-se com saúde e com estado subjetivo de saúde, a qualidade de vida não inclui somente fatores relacionados à saúde, tais como bem-estar físico, funcional, emocional e mental, mas também elementos não relacionados à saúde como trabalho, família, amigos e circunstâncias de vida. Mediante isto, a Subescala 02 da Escala de Bem-Estar Subjetivo, teve como objetivo identificar opiniões que os participantes compartilham sobre a sua própria vida no momento atual.

Tabela 3 - Subescala 2

\begin{tabular}{|c|c|c|c|}
\hline \multicolumn{4}{|c|}{ Escala de Bem Estar Subjetivo } \\
\hline \multicolumn{4}{|l|}{ Subescala 2} \\
\hline & Total & Média & $\begin{array}{l}\text { Desvio } \\
\text { Padrão }\end{array}$ \\
\hline Gosto da minha vida & 122 & 4,06 & 0,82 \\
\hline Considero-me uma pessoa feliz & 108 & 3,60 & 1,13 \\
\hline $\begin{array}{l}\text { A minha vida está de acordo com o que } \\
\text { desejo para mim }\end{array}$ & 107 & 3,56 & 2,02 \\
\hline Minha vida poderia ser melhor & 99 & 3,30 & 1,44 \\
\hline Mudaria meu passado se pudesse & 97 & 3,23 & 1,43 \\
\hline Estou satisfeito com a minha vida & 96 & 3,20 & 1,27 \\
\hline Avalio minha vida de forma positiva & 85 & 2,83 & 1,20 \\
\hline $\begin{array}{l}\text { Sob quase todos os aspectos minha vida está } \\
\text { longe do meu ideal de vida }\end{array}$ & 84 & 2,80 & 1,29 \\
\hline Estou insatisfeito com a minha vida & 84 & 2,80 & 1,15 \\
\hline $\begin{array}{l}\text { Tenho conseguido tudo o que esperava na } \\
\text { vida }\end{array}$ & 83 & 2,76 & 1,16 \\
\hline Minha vida é "sem graça" & 83 & 2,76 & 1,25 \\
\hline Minha vida está ruim & 82 & 2,73 & 1,08 \\
\hline $\begin{array}{l}\text { Tenho mais momentos de tristeza do que de } \\
\text { alegria na minha vida }\end{array}$ & 42 & 2,93 & 1,36 \\
\hline
\end{tabular}


Os resultados deste subteste permitiu identificar que as principais opiniões que os participantes compartilharam sobre a sua vida foram positivas, sendo estas: "Gosto da minha vida"; "A minha vida está de acordo com o que desejo pra mim"; "Considero-me uma pessoa feliz".

Nas tabelas apresentadas nesse estudo foram destacados os totais obtidos em cada item dos instrumentos utilizados, a média obtida em cada item o desvio padrão das respostas. A média foi destacada anteriormente que consiste no ponto de equilíbrio das frequências. Já o desvio padrão de acordo com Field(14), representa a média dos desvios a partir da média, assim o desvio padrão das diferenças entre condições representa o desvio médio da diferença das médias, ou seja, é a medida que permite verificar qual a variação existe entre a diferença dos escores dos participantes.

\section{CONSIDERAÇÕES FINAIS}

As dificuldades sociais frente ao primeiro emprego e a deficiência no preparo de profissionais capacitados para adentrar as organizações exige uma ampla avaliação das políticas sociais em curso e como tem ocorrido, de fato, o preparo desse adolescente que almeja alcançar tal colocação.
Neste trabalho pode-se perceber que apesar do aumento dos níveis de desemprego no nosso país e a dificuldade de encontrar novos profissionais bem preparados para o mercado de trabalho, os jovens continuam a serem preparados para se tornarem trabalhadores assalariados, além do mais, percebe-se que os adolescentes participantes desta pesquisa apresentam sentimentos $\mathrm{e}$ crenças positivas, se sentem bem, empolgados, determinados, decididos, interessados e ansiosos para alcançar os seus objetivos em comum, 0 primeiro emprego.

Percebe-se também que os pensamentos de tais participantes são funcionais, de acordo com a pesquisa eles gostam da sua vida, consideram a vida de acordo com aquilo que deseja para si e se consideram pessoas felizes, fatores que influenciam de maneira positiva nesse processo de preparação para a colocação no mercado de trabalho, além disto, apresentam um perfil de liderança maduro, destacando características como: Responsabilidade, foco, ética, conduta de afeto, proteção, apoio, compreensão e cooperação, que são imprescindíveis para o crescimento profissional do próprio sujeito no mercado de trabalho enquanto colaborador e da organização que esse sujeito estivesse inserido. 
Mediante isto, conclui-se que a pesquisa alcançou satisfatoriamente seu objetivo e abre porta para pesquisas futuras com outras turmas de adolescentes que estejam também inseridos em algum

\section{REFERÊNCIAS}

1. Cacciamali MA, Tatei F. Impacto do Desemprego e da Informalidade sobre a Empregabilidade e a Renda Futura do Jovem. In: Instituto de Pesquisa Econômica Aplicada. Boletim Regional, Urbano e Ambiental. 1aㅗ ed. Brasília: Ipea; 2017.

2. Eisenstein E. Adolescência: definições, Conceitos e Critérios. Rev Adolescência \& Saúde 2005; 2 (2): 1-2.

3. Sousa H, Frozzi D, Bardagi MP. Percepção de Adolescentes Aprendizes Sobre a Experiência do Primeiro Emprego. Rev Psicologia Ciência e Profissão 2013; 33 (4): 918-933.

4. Becker D. O que é Adolescência. $1^{\underline{a}}$ ed. eBook Tatuapé (SP): Brasiliense; 2017.

5. Bravo MS. Aprender a Dirigir aos 18 Anos de Idade: Uma Visão da Psicologia Nessa Fase da Adolescência. Rev Boletim de Psicologia 2015; 65 (143): 147-155.

6. Zappe JG, Moura JFM Jr, Dell'aglio DD, Sarriera JC. Expectativas Quanto Ao Futuro De Adolescentes Em Diferentes Contextos. Rev Acta Colombiana de Psicologia 2013; 16 (1): 91-100.

7. Godoy SL, Noronha APP. Instrumentos psicológicos utilizados em seleção programa Jovem Aprendiz e também com adolescentes que não estão inseridos em nenhum programa para que sejam identificados os aspectos de ambos os grupos. profissional. Rev do Departamento de Psicologia - UFF 2005; 17 (1): 139-159.

8. Baumgartl VO, Pereira A, Lacerda J. A utilização de testes psicológicos em organizações de Minas Gerais. Rev Arquivos Brasileiros de Psicologia 2010; 62 (2): 178-186.

9. Scorsolini-Comin F, Santos, Manoel A. Psicologia Positiva e os Instrumentos de Avaliação no Contexto Brasileiro. Rev Psicologia: Reflexão e Crítica 2010; 23 (3): 440-448.

10. Matos RA. Inventário de Atitudes no Trabalho. Rev Mãos Dadas [200--].

11. Paiva M. Matemática e. Rev Agora 1997; 1 (2): p. 3.

12. Bunchaft G, Vasconcellos VLP. Padronização do Teste Desiderativo no Contexto da Análise Transacional: Resultados Preliminares. Rev Psicologia: Teoria e Pesquisa 2001; 17 (1): 19-25.

13. Albuquerque AS, Tróccoli BT. Desenvolvimento de Uma Escala de BemEstar Subjetivo. Rev Psicologia: Teoria e Pesquisa 2004; 20 (2): 153-164.

14. Field A. Descobrindo a Estatística Usando o SPSS. 2. ed. Porto Alegre: Atmed; 2009.

\section{Como citar (Vancouver)}

Moraes HCP, Rocha VHC, Bergamini GB, Samuelsson E, Joner C, Schneider LF et al. Primeiro emprego: o perfil do adolescente e o papel do psicólogo frente a esta nova etapa. Rev Cient Fac Educ e Meio Ambiente [Internet]. 2017;8(2):17-30. DOI: http://dx.doi.org/10.31072/rcf.v8i2.546 